\title{
FORMATION OF THIAMINE DISULFIDE BY FERRICYANIDE AND ITS DEPENDENCY ON PH OF THE REACTION MEDIA
}

\author{
CHIKATARO KAWASAKI, TAKATOMO HORIO AND ISAMU DAIRA ${ }^{1}$ \\ The School of Pharmacy, Osaka University, Toyonaka
}

(Received February 24, 1964)

It was reported in the previous papers $(1,2)$ that the oxidation of thiamine by alkaline ferricyanide was a reaction always yielding thiamine disulfide (TDS) as a byproduct and the effect of oxygen dissolved in the medium on the production of TDS and thiochrome was investigated. It was further found that thiochrome was poorly produced even when thiamine was immediately oxidized by ferricyanide reagent in an alkaline medium at $\mathrm{pH} 11$ to 12 , whereby a marked production of TDS was detected by paper chromatography (3). When the production of TDS was determined thrugh the adsorption of TDS on Amberlite IRC-50 by ferricyanide oxidation of thiamine solution at alkaline $\mathrm{pH}$ levels, the production of TDS reached its maximum at $\mathrm{pH}$ 11.6. Under these conditions, TDS was produced from thiamine in a high yield, which seemed to be of interest as a synthetic method of TDS.

\section{EXPERIMENTAL aND RESULTS}

\section{Effect of $p H$ on Formation of TDS}

Buffer solutions, $\mathrm{pH} 8.7,9.6,10.6,11.6$ and 13.1, were prepared as given in the preceding paper (4).

Immediate Addition of Ferricyanide after pH Adjustment - To $5 \mathrm{ml}$ of thiamine solution $(2 \mathrm{mg} / \mathrm{ml}), 5 \mathrm{ml}$ of the buffer was added and mixed. Immediately $3 \mathrm{ml}$ of $1 \%$ ferricyanide was added. After a definite interval, $1.3 \mathrm{ml}$ each of the solution was pipetted out and dilute $\mathrm{HCl}$ and water were added up to $100 \mathrm{ml}$ and $\mathrm{pH} 4.8$. To $2 \mathrm{ml}$ of the diluted solution was added $8 \mathrm{ml}$ of water and the mixture was passed through an Amberlite IRC-50 column. Thus the amount of TDS was determined as described in the preceding paper. The results were shown in Fig. 1.

Delayed Addition of Ferricyanide after $\mathrm{pH}$ Adjustement - To $5 \mathrm{ml}$ of thiamine solution $(2 \mathrm{mg} / \mathrm{ml}), 5 \mathrm{ml}$ each of the buffer of various $\mathrm{pH}$ levels was added and the whole was allowed to stand for various periods. To $1 \mathrm{ml}$ of the solution was added $0.3 \mathrm{ml}$ of $1 \%$ ferricyanide and the volume was adjusted with dilute $\mathrm{HCl}$ and water up to $100 \mathrm{ml}$ and $\mathrm{pH}$ 4.8. The amounts of TDS and thiochrome of this solution were determined with the results shown in Fig. 2.

\footnotetext{
1 川崎近太郎, 堀尾嘉友, 大良勇。
} 


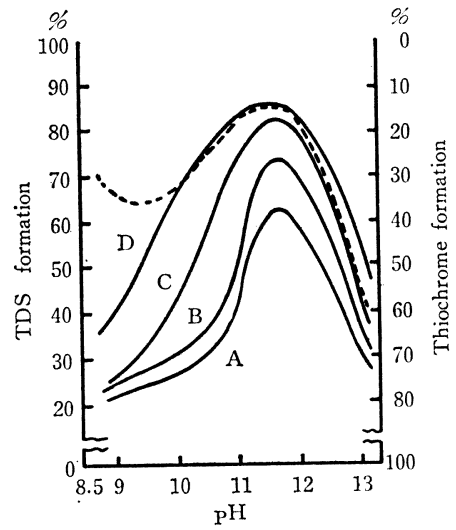

Fig. 1 Formation of TDS from Alkaline Thiamine by Ferricyanide Reagent Ferricyanide was added immediately after the solution was made alkaline. The mixture was made acidic and after dilution, the amount of TDS or thiochrome was determined.

-, TDS produced ; A, immediately ; B, after $2 \mathrm{~min} ; \mathrm{C}$, after $5 \mathrm{~min}$; $\mathrm{D}$, after $30 \mathrm{~min}$; -.--, thiochrome produced.

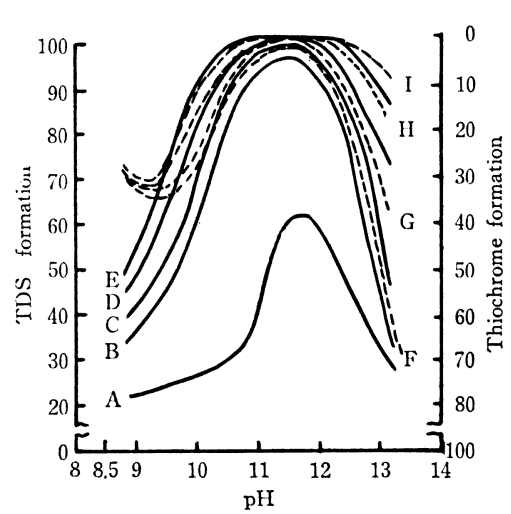

F1G. 2 TDS Formation from Alkaline Thiamine by Delayed Addition of Fer. ricyanide Reagent

Ferricyanide was added after thiamine had been left standing for certain periods in an alkaline solution. The mixture was made acidic and after dilution TDS or thiochrome produced was determined.

-, TDS produced; A, immediately; B, after $5 \mathrm{~min}$; C, after $10 \mathrm{~min}$; D, after $30 \mathrm{~min}$; $\mathrm{E}$, after $60 \mathrm{~min} ; \cdot \cdots$, thiocheome produced; $\mathrm{F}$, after $5 \mathrm{~min} ; \mathrm{G}$, after $10 \mathrm{~min} ; \mathrm{H}$, after $30 \mathrm{~min}$, I, after $60 \mathrm{~min}$.

\section{Production of TDS by Ferricyanide at pH 11 to 12}

Ten grams of thiamine hydrochloride was dissolved in $70 \mathrm{ml}$ of water and the $\mathrm{pH}$ was adjusted to $11.7-11.8$ by addition of $10 \% \mathrm{NaOH}$. To this solution a ferricyanide solution (11 $\mathrm{g} \mathrm{K}_{3} \mathrm{Fe}(\mathrm{CN})_{6}$ was dissolved in $50 \mathrm{ml}$ water) was slowly added, whereby the solution became turbid and the temperature rose to about $30^{\circ}$. After standing at room temperature for 3 hours, a yellow, oily precipitate appeared at the bottom of the vessel. The supernatant fluid was decanted and the yellow oily residue was dissolved in about two volumes of ethanol, followed by filtration. About 20 volumes of acetone was added to the filtrate and the vessel wall was rubbed with a glass rod, whereby white rhombic crystals separated out. After standing overnight in the cold, about $7.6 \mathrm{~g}$ crystals melting at 85 to $92^{\circ}$ were obtained. Analysis for TDS $\left(\mathrm{CH}_{3}\right)_{2} \mathrm{CO} \cdot \mathrm{H}_{2} \mathrm{O}$, i.e., $\mathrm{C}_{27} \mathrm{H}_{42} \mathrm{~N}_{8} \mathrm{~S}_{2} \mathrm{O}_{6}$. Calcd. : C, $50.92 \% ; \mathrm{H}, 6.65 \%$; N, 17.60. Found: C, 51.14\%; H, 6.62\%; N, $17.67 \%$. After drying in a desiccator with calcium chloride, the melting-point of the crystals rose further, reaching finally $134^{\circ}$ after seven days. By drying the raw crystals in a $\mathrm{P}_{2} \mathrm{O}_{5}$-desiccator at $50^{\circ}$, the melting-point rose to $177-178^{\circ}$ (decomp.). Three grams of the crude crystals were dissolved in $2.5 \mathrm{ml}$ of water, to which $50 \mathrm{ml}$ of ethanol was added. To the filtrate $200 \mathrm{ml}$ of ether was added and the solution was placed overnight in a refrigerator. The crystals thus separated gave a melting-point of $57-60^{\circ}$, which rose to $177-178^{\circ}$ (decomp.) after drying in vacuo on $\mathrm{P}_{2} \mathrm{O}_{5}$. Analysis for TDS; $\mathrm{C}_{24} \mathrm{H}_{34} \mathrm{~N}_{8} \mathrm{O}_{4} \mathrm{~N}_{2}$ : Calculated C, $50.22 \% ; \mathrm{H}, 6.09 \% ; \mathrm{N}, 19.91 \%$. Found : 
C, $50.91 \% ; \mathrm{H}, 6.07 \% ; \mathrm{N}, 19.61 \%$. The infrared spectra of the raw and purified crystals showed a good coincidence with that of the authentic sample.

Besides this, two kinds of crystals having melting-points of $50-60^{\circ}$ and $128-134^{\circ}$, respectively, were simultaneously obtained. Under some conditions, no oily substance appeared. In this case, pale yellow crystals, scarcely soluble in water, having the melting-point of $134^{\circ}$, were obtained after the concentrated solution was allowed to stand overnight. The crystals, after dissolution in a large amount of hot water, could be converted into readily water-soluble crystals, having a melting-point of $50-60^{\circ}$, which were dehydrated into anhydrous crystals by further purification. The $R_{F}$ values of all these samples (detected by Dragendorff reagent) on the paper chromatogram were found to be 0.56 (Toyo Filter paper No. 50, ascending method, at room temperature, developed with watersaturated $n$-butanol.)

\section{Ferricyanide Oxidation of Thiamine Homologs at pH 11 to 12}

Synthesis of O-Benzoylthiamine Disulfide from O-Benzoylthiamine Hydrochloride- (a) Three grams of $O$-benzoylthiamine hydrochloride was dissolved in $280 \mathrm{ml}$ water. The $\mathrm{pH}$ of the solution was adjusted to 11.7 with $\mathrm{N} \mathrm{NaOH}$, to which a mixture of $3 \mathrm{ml}$ of ferricyanide solution and $30 \mathrm{ml}$ of water was slowly added, whereby pale yellow or white needles appeared. The crystals were separated by filtration, and dissolved in $\mathrm{CHCl}_{3}$. After evaporation of the solvent, they were recrystallized from ethyl acetate to give pure crystals, melting at $146^{\circ}$ (decomp.). Mixed melting point with authentic $O$-benzoylthiamine disulfide (BTDS), showed no depression and by paper chromatography they gave a $R_{\mathrm{F}}$ value of 0.87 , as detected by Dragendorff reagent (Toyo Filter Paper No. 50, ascending method, room temperature, developed with water-saturated $n$-butanol). The yield was 1.7 g. (b) $5 \mathrm{~g}$ of $O$-Benzoylthiamine hydrochloride was dissolved in $25 \mathrm{ml}$ of water and the $\mathrm{pH}$ of the solution was adjusted to 11.8 with $1 \mathrm{~N} \mathrm{NaOH}$. $50 \mathrm{ml}$ of ferricyanide solution $(10 \mathrm{~g}$ per $100 \mathrm{ml}$ ) was slowly added to the solution, whereby yellowish resinous substance was separated. After extraction with $\mathrm{CHCl}_{3}$, the substance was recrystallized from ethanol, giving $3.7 \mathrm{~g}$ of the crystals, melting at $146-7^{\circ}$ (decomp.). Analysis for BTDS; $\mathrm{C}_{38} \mathrm{H}_{42} \mathrm{~N}_{8} \mathrm{O}_{6} \mathrm{~S}_{2}$. Calcd: C, $59.18 \% ; \mathrm{H}$, $5.49 \%$. Found: C, $58.84 \% ; \mathrm{H}, 5.70 \%$.

Synthesis of O-Methylthiamine Disulfide from O-Methylthiamine Hydrochloride — Ten grams of crude $O$-methylthiamine hydrochloride (mp 226- $8^{\circ}$ ) $(5,6)$ was dissolved in $50 \mathrm{ml}$ of water and the $\mathrm{pH}$ was adjusted to 11.6 with $\mathrm{N}$ $\mathrm{NaOH}$. After addition of $50 \mathrm{ml}$ of $20 \%$ ferricyanide solution, the solution was allowed to stand, whereby needles were separated. After standing for three hours, the crystals were collected, dissolved in ethanol and after addition of acetone they were allowed to cool, whereby $3.7 \mathrm{~g}$ of the crystals melting at $95-97^{\circ}$ were obtained with a yield of $48 \%$. Analysis for $\mathrm{O}$-methylthiamine disulfide, $\mathrm{C}_{26} \mathrm{H}_{38} \mathrm{~N}_{8}$ $\mathrm{O}_{4} \mathrm{~S}_{2} \cdot \mathrm{H}_{2} \mathrm{O}$. Calcd: C, $51.27 \% ; \mathrm{H}, 6.63 \% ; \mathrm{N}, 14.42 \%$; Found: C, $50.97 \% ; \mathrm{H}$, $6.96 \% ; \mathrm{N}, 14.47 \%$.

Deoxythiamine Disulfide from Deoxythiamine Hydrochloride-—Five grams of deoxythiamine hydrochloride ( $\mathrm{mp} 256^{\circ}$, decomp.) was dissolved in $40 \mathrm{ml}$ of water and the $\mathrm{pH}$ was adjusted to 11.7 by addition of $10 \% \mathrm{NaOH}$. To this solution $25 \mathrm{ml}$ of $20 \%$ ferricyanide solution was slowly added, whereby yellowish resinous 
substance appeared. After standing overnight at room temperature, the supernatant was discarded and $30 \mathrm{ml}$ of ethanol was added to the residue. The filtrate was concentrated in vacuo to one-half volume. Colorless needles were separated by the addition of $100 \mathrm{ml}$ acetone. After standing overnight in the cold, $3.2 \mathrm{~g}$ of the crystals $\left(\mathrm{mp} 166-7^{\circ}\right)$ was obtained with a yield of $77.5 \%$. The crystals obtained by recrystallization from alcohol melted at $157^{\circ}$, but after drying on $\mathrm{P}_{2} \mathrm{O}_{5}$ in vacuo, they melted at $166^{\circ}$. Analysis for deoxythiamine disulfide, $\mathrm{C}_{24} \mathrm{H}_{34} \mathrm{~N}_{8} \mathrm{O}_{2} \mathrm{~S}_{2}$. Calcd : C, 54.31\%; H, $6.46 \% ; \mathrm{N}, 21.11 \%$. Found: C, $54.23 \% ; \mathrm{H}, 6.40 \% \mathrm{~N}, 20.98 \%$. Paper chromatography: $R_{\mathrm{F}} \quad 0.80-0.81$ (water-saturated $n$-butanol); 0.52 (acetic acid- $n$-butanol-water, $1: 4: 5$ ). Infrared spectra of $O$-methylthiamine disulfide and deoxythiamine disulfide were shown in Fig. 3.

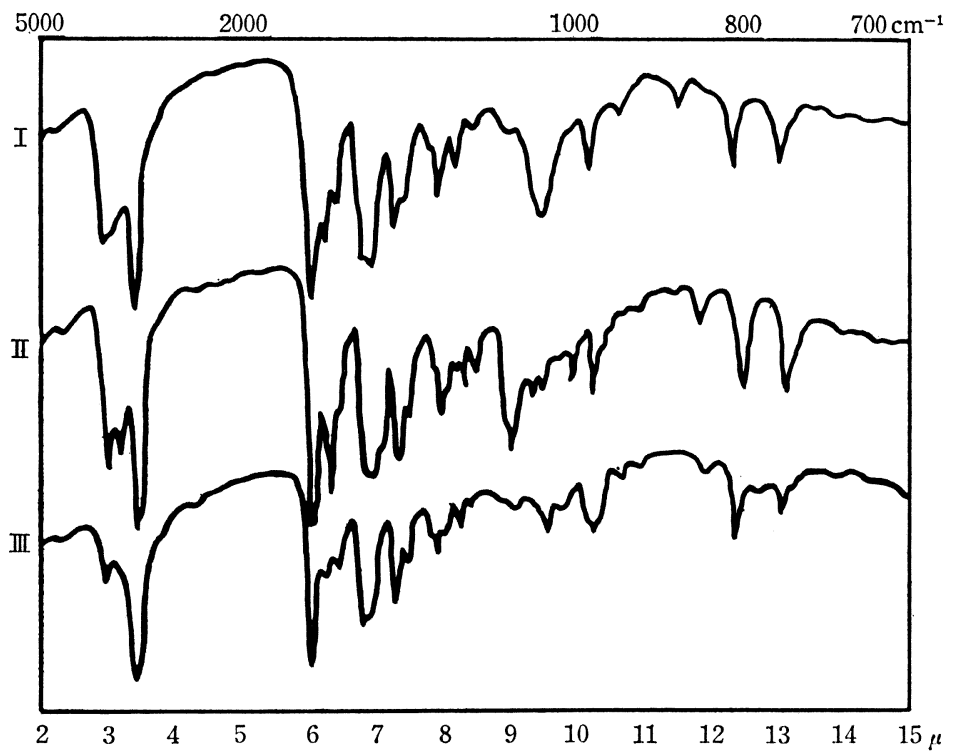

FIG. 3 Infrared Spectra of T'DS (I), O-Methylthiamine Disulfide (II) and Deoxythiamine Disulfide (III) (in Nujol)

\section{DISCUSSION}

It has been reported that the disulfide derivative of benzothiazole or $\mathrm{N}$-benzylthiazolium can be synthesized by oxidation with ferricyanide, $\mathrm{H}_{2} \mathrm{O}_{2}$, or iodine after the thiazole ring of the compounds had been opened by treatment with $\mathrm{NaOH}$ (7) and that the disulfide of 4-hydroxythiamine or of $N$-methylthiamine can also be synthesized by oxidation with alkaline ferricyanide (8). TDS can also be synthesized by adding one mole ferricyanide reagent to a mixture of 1 mole thiamine and 3 moles $\mathrm{NaOH}$ (9). As described in the preceding paper, thiochrome was poorly produced at $\mathrm{pH} 11$ and 12 when the ferricyanide reagent was added immediately after the solution was made alkaline. TDS was predominantly produced and the production of thiochrome was increased beyond that $\mathrm{pH}$ range. As shown in Fig. 
1 , the production of TDS was $62 \%$ immediately after addition of ferricyanide and $82 \%$ after 5 minutes in contrast to low production at other $\mathrm{pH}$ levels. If the rise in TDS production at various $\mathrm{pH}$ levels is compared between immediately and after 30 minutes, the production was highest between $\mathrm{pH} 11$ to 12 . That the production of TDS is low at $\mathrm{pH}$ above 13, is due to greater production of thiochrome than at any other $\mathrm{pH}$ levels. The fluorescent substance produced at $\mathrm{pH} 13$ was identified as thiochrome not only by ultraviolet absorption spectrum, but also by isolation of the pure crystals of thiochrome.

It has already been reported that thiamine, having been left standing in an alkaline solution, produces thiamine disulfide by following addition of ferricyanide (8-10). As seen in Fig. 2, the formation of TDS reaches its maximum at $\mathrm{pH}$ 11.6, whereas at other $\mathrm{pH}$ levels the formation of thiochrome increased. But the amount of thiochrome produced was reduced with the lapse of minutes at $\mathrm{pH}$ above 13, and at the same time TDS production was increased. Finally, the formation of TDS became the main reaction. Hence, it is clear that the thiamine solution, which has been left standing at $\mathrm{pH}$ above 11, exclusively produces TDS by addition of ferricyanide. Employing such conditions under which TDS is easily formed from thiamine, the disulfide can be quantitatively obtained even at high concentrations. The disulfide compounds thus synthesized by ferricyanide oxidation are almost colorless in crude crystals and can be obtained with high yield in comparison with the preparation by alkaline iodine oxidation. It can therefore be said to be an excellent synthetic method of thiamine disulfide. The main reaction products of ferricyanide oxidation of thiamine are thiochrome and TDS. The ratio of both the compounds was found to be dependent on $\mathrm{pH}$, oxygen dissolved in the medium and the lapse of minutes after the solution was made alkaline.

\section{SUMMARY}

Thiamine disulfide produced from thiamine in an alkaline medium immediately after adding ferricyanide solution or after allowing to stand for some time was determined by adsorption on and elution from Amberlite IRC-50. The formation was maximal at $\mathrm{pH}$ around 11.6, decreasing at other $\mathrm{pH}$ levels. Addition of ferricyanide after the solution was left standing for some time in an alkaline medium, resulted in production of less thiochrome and more thiamine disulfide with the lapse of minutes. The oxidation of thiamine with ferricyanide produces both thiochrome and thiamine disulfide simultaneously, but at $\mathrm{pH} 11$ to 12 , thiamine disulfide was predominantly produced and the reaction can be used as a practical synthetic method of the disulfide.

\section{ACKNOWLEDGEMENT}

The authors wish to express their gratitude to Dr. Kiyoshi Tsutsui, director of the Central Laboratory of Dai-Nippon Seiyaku Co. Ltd., and to Dr. Jo Fukuda and of our university for elementary analyses. 


\section{REFERENCES}

1. Horio, T., Vitamins 21, 517 (1960).

2. Horio, T., ibid. 24, 88 (1961).

3. Horio, T., ibid. 24, 79 (1961).

4. Horio, T., ibid. 21, 520 (1960).

5. Clarke, H. T., and Gurin, S. T., Amer. Chem. Soc. 57, 1876 (1935).

6. Yurugi, S., and Fushimi, T., Yakugaku Zasshi 77, 264 (1957).

7. Mils, W.H., and Clarke, L.M., and Aeschliman, J.A., J. Chem. Soc. 1923, 2353.

8. Nesbitt, P., and Sykes, p., ibid. 1954, 4585.

9. Wornat, K., U.S.P. 2, 458, 453 (1949).

10. Matsukawa, T, and Hirano, H. Vitamins 13, 362 (1957). 